Rochester Institute of Technology

RIT Scholar Works

Articles

Faculty \& Staff Scholarship

Fall 10-19-2018

\title{
Re-playing Maimonides' Codes: Designing Games to Teach Religious Legal Systems
}

Owen Gottlieb

Rochester Institute of Technology

Follow this and additional works at: https://scholarworks.rit.edu/article

Part of the African History Commons, Ancient, Medieval, Renaissance and Baroque Art and Architecture Commons, Bilingual, Multilingual, and Multicultural Education Commons, Cultural History Commons, Curriculum and Instruction Commons, Educational Technology Commons, Ethics in Religion Commons, Game Design Commons, History of Religion Commons, History of Religions of Western Origin Commons, Instructional Media Design Commons, Intellectual History Commons, Interactive Arts Commons, Interdisciplinary Arts and Media Commons, Islamic World and Near East History Commons, Jewish Studies Commons, Legal Commons, Legal Theory Commons, Medieval History Commons, Medieval Studies Commons, Other Legal Studies Commons, Practical Theology Commons, Religion Law Commons, Religious Education Commons, Religious Thought, Theology and Philosophy of Religion Commons, and the Torts Commons

\section{Recommended Citation}

Gottlieb, Owen (2018). Re-playing Maimonides' codes: Designing games to teach religious legal systems. In Teaching Theology \& Religion: Vol. 21 Issue 4 (pp. 246-259). Wiley \& Sons, Inc.

This Article is brought to you for free and open access by the Faculty \& Staff Scholarship at RIT Scholar Works. It has been accepted for inclusion in Articles by an authorized administrator of RIT Scholar Works. For more information, please contact ritscholarworks@rit.edu. 
Appears in:

Gottlieb, Owen (2018). Re-playing Maimonides' codes: Designing games to teach religious legal systems. In Teaching Theology \& Religion: Vol. 21 Issue 4 (pp. 246-259). Wiley \& Sons, Inc.

Author's Pre-Print:

Re-playing Maimonides' Codes: Designing Games to Teach Religious Legal Systems

\author{
Owen Gottlieb
}

School of Interactive Games and Media

Golisano College of Computing and Information Sciences

and

Initiative in Religion, Culture, and Policy, MAGIC Center

Rochester Institute of Technology

Keywords

design learning, education, games and learning, Jewish studies, Judaism, medieval history, religious education, religious law 


\section{Re-playing Maimonides' Codes: Designing Games to Teach Religious Legal Systems ${ }^{1}$}

\section{Introduction}

How could three lines in the book of Deuteronomy become a tabletop and mobile game for learning?

If you see your fellow's ox or sheep gone astray, do not ignore it; you must take it back to your fellow. If your fellow does not live near you or you do not know who he is, you shall bring it home and it shall remain with you until your fellow claims it; then you shall give it back to him. You shall do the same with his ass; you shall do the same with his garment; and so too shall you do with anything that your fellow loses and you find: you must not remain indifferent. (Deuteronomy 22:1-3, Jewish Publication Society [1985])

Many chapters of Jewish legal codes, debates, and rulings regarding the return of and care for lost and found objects stem from these three Biblical verses. This corpus of legal material developed over the course of centuries. The first post-biblical legal code, the Mishna, understood to have been assembled by Rabbi Judah the Patriarch based on a broad collection of oral traditions during the second half of the $2^{\text {nd }}$ century CE in northern

\footnotetext{
${ }^{1}$ Funding Acknowledgements: The tabletop games Lost \& Found and Lost \& Found: Order in the Court - the Party Game were supported by the Golisano College of Computing and Information Sciences, the Office of the Vice President for Research, and the MAGIC Center at the Rochester Institute of Technology. The digital prototype version of Lost \& Found was supported and funded by the National Endowment for the Humanities. Any views, findings, conclusions, or recommendations expressed in this paper do not necessarily represent those of the National Endowment for the Humanities.
} 
Palestine, provides a succinct set of laws giving structure to how a population might live their daily lives shaped by the Torah. Centuries later, the Babylonian Talmud, redacted circa $650 \mathrm{CE}$, substantially expanded the Mishna in the form of legal debates and stories. From 1170 to 1180 CE, in Fustat (Old Cairo), Moses Maimonides, the great physician, rabbi, legal scholar, and philosopher, wrote a new legal code. In his 14-volume Mishneh Torah, Maimonides strove to provide a system of laws that responded to the people and the needs of his time, crystalizing a voluminous and confusing heritage of debates into a manageable form. In his code, Maimonides considers the long history of Talmudic debates and the Mishna, but he does not cite his sources. Partly due to the lack of citation and partly due to Maimonides' perceived arrogance in totally restructuring Jewish law from the ground up, the Mishneh Torah became the center of great controversy, but it eventually took its place as a cornerstone in the Jewish legal tradition.

Maimonides, who strove to synthesize Aristotelian philosophy and classical Jewish texts, was certainly influenced by great Islamic philosophers and jurists. Fustat in his time was a crossroads of Islamic, Jewish, and Christian life. As I searched for a source from which to begin building a game to teach about religious legal codes, I found that Mishneh Torah provided laws stated in succinct form, important for designing game rules. Furthermore, it also provided a distillation of earlier legal debates from a crossroads of cultural production. With the Mishneh Torah, I found a text from which I could derive a set of games about Jewish legal codes, and eventually Islamic codes, with the potential for exploration of Christian life at the time as well. It would become the heart of the first two modules of the Lost \& Found game series (see figure 1 [insert]).

In this article, I present the first two games of the Lost \& Found series, the background leading to my broader work in games and teaching religion, as well as the specific context for the 
Lost \& Found series. By grounding these pursuits in the Games and Learning field, I hope to open that field to other educators. I provide a design case-study, discussing the rationale behind working to teach religious legal systems more broadly, then turn to the hermeneutics influencing the approach to understanding the legal system being modeled, and close with a discussion of the kind of teaching and learning involved in the design of the games, and early-stage data on the public play of the games.

Understanding the form of design cases will be important for readers new to such scholarly approaches, as this article does not show generalizable social science regarding teaching and learning, but rather provides insights through specific case analysis of design processes. Design cases use detailed exploration of design processes in order to provide design knowledge in context, specifically providing accounts of precedent for other designers (Boling, 2010; Howard, 2011; Smith, 2010). My colleagues and I conducted initial “small n" human subjects research (studies with a low number of participants) examining talk-practice of players of the first game in the game series. These early studies eventually led to the design and development of the second game in the series to broaden options for learner interaction in the classroom or informal learning environment (Gottlieb \& Schreiber, forthcoming). The team will be conducting wider human-research studies as the project grows. The emphasis of this article is different, drawing from internal design review and playtesting (not human subjects research), and taken from over three years of design meeting notes, prototypes, and documentation such as team white papers.

The design case in this paper provides a particular example in a specific context of how learning games designers mixed three kinds of developing design knowledge: content knowledge, pedagogical content knowledge (Shulman, 1986), and game design knowledge in the process of creating new design artifacts for learning environments. The content knowledge 
includes a number of topics ranging from familiarity of architecture of the historical period to render illustrations, to understanding terms of art in religious law as well as implications of the laws and principles underlying the laws. Developing content knowledge for the design team ranged from understanding the value of historical coinage to coming to learn that there were monsoons in Egypt during the period, to reasoning through implications of the legal system to notions of justice, fairness, and governance. The pedagogical content knowledge ranged from methods and modes of teaching the team members how to unpack the laws to understand underlying principles to how variant cases might be understood. Pedagogical content knowledge was also important for leading scaffolded discussions and conducting discourse analysis-based data gathering during playtests. Both the discussion and data analysis suggest different ways to use the developing game as a part of learning environments. Regarding game design knowledge, this third discipline is crucial. The team had to apply and further develop game design skills through an iterative design process. The case here shows how such a mix of knowledge types are applied to developing these specific educational intervention artifacts - two games.

The Games: Lost \& Found and Lost \& Found: Order in the Court - The Party Game

To ground the discussion of design and play below, it is important to have a basic understanding of the games at the heart of the discussion. Lost \& Found describes a series of games created by faculty and students at the Initiative in Religion, Culture, and Policy (RCP) at the MAGIC Center at RIT, the Rochester Institute of Technology (magic.rit.edu/rcp). The team is bolstered by consulting faculty at a number of universities and institutions. The first game in the series, Lost \& Found (Gottlieb, Schreiber, \& Murdoch-Kitt, 2017) (see Figure 1[insert]) (referred to in this article as Lost \& Found) is a tabletop to mobile strategy game targeted to high school and undergraduate learners. This means it is a card game that is intended to also have a 
mobile version. Games such as Settlers of Catan (Teuber, 1996), Agricola (Rosenberg, 2007) and other popular tabletop board and card games often have digital and/or mobile versions. The second game, Lost \& Found: Order in the Court - the Party Game (referred to in this article as Order in the Court) (Gottlieb \& Schreiber, 2017) is a storytelling party game, targeted to middle school students and up. Both are oriented towards teaching about aspects of Mishneh Torah's religious legal system, specifically the tort laws dealing with lost and found objects.

In the strategy game Lost \& Found, two to five players take on the roles of villagers or city dwellers in Fustat (Old Cairo) in the 12th century, where Maimonides wrote Mishneh Torah. The illustrations (in print and digital) and music (in the digital mobile prototype) are period accurate, rendering the time and locale. Players are tasked with balancing the needs of the community with those of their own family. Any number of players can win the game and any number of players can lose over the course of play, which takes just over an hour. If any player becomes "destitute" (unable to care for themselves), then all players lose. All players can also lose in a "disaster" situation if they do not work together to avert that disaster. In order to win the game, players must fulfill two interlocking requirements. In order to be eligible to win, the players must cooperatively contribute to and complete six of ten "communal responsibilities," such as training a doctor (see Figure 2 [insert]), building a bathhouse, training a judge, and having clean water (based on Talmud Sanhedrin 17b and Mishneh Torah Hilkhot De'ot 4:23). If by the end of game six communal responsibilities have not been fulfilled, all players lose. If the six communal responsibilities have been fulfilled by end of game, then any players who have also completed three family responsibilities, win. Family responsibilities include teaching your child a trade and teaching your child to swim. These responsibilities are drawn from a passage on a father's responsibilities to a son in the Talmud Kiddushin 29a and Talmudic and Mishnaic commentaries. 
The number of required family responsibilities may be modified near end-of-game based on the behavior of the players during the game. For example, if you are caught after having stolen something earlier in the game, you may have to work harder at a chance of winning. If you have been particularly helpful to your neighbors, you may find it easier to win. These modifications are managed by draws from a heshbon (accounting) deck (see Figure 3 [insert]) that serves to introduce some chance into your social decision (as opposed to predictable reward and punishment). ${ }^{2}$

During gameplay, players manage resources such as animals, vessels with honey, milk, wine, and coins while addressing events over the course of a year. Events often have to do with losing or finding objects and these objects are marked as owned by particular players or NPCs (nonplayer characters). Players have to decide whether to follow the laws, break the laws, or go above and beyond the laws regarding the return of lost objects. All the while they have to work with other players to fulfill communal responsibilities and advance their own family responsibilities. In this way, the game simulates addressing legal situations.

Order in the Court, which was developed with the intention of use with different curricular scaffolding than Lost \& Found, is a party game for three to five players and can be played in about thirty minutes. In Order in the Court, players compete for points as the position of judge rotates from player to player. Players draw story cards and use those story cards to craft an explanation for a legal ruling from Mishneh Torah that the judge reads from a Ruling Card. This is often played for humor. The explanation of the legal rulings (which are often arcane or

\footnotetext{
${ }^{2}$ For detail on textual sources for the responsibilities in Talmud and Mishneh Torah, see Gottlieb (2017).
} 
ambiguous) is on the reverse side of the Ruling Card and can be revealed at the end of a round if players are curious. I will discuss this in greater detail in the section below regarding play.

I will now move on to discuss my background in creating Games for Learning in the study of religion.

\section{A Path to Jewish Games for Learning}

From where does this work in Jewish Games and Learning originate? What is the context of the creation of these games? I have previously written about what I argue is a longstanding tradition of games, play, and rabbinic literature (Gottlieb, 2015). Some of my designer-researcher stance and background can provide context for the development of these games. Over the last seven years, my design and research work has been dedicated to the teaching and learning of Jewish studies and comparative religion through games and game design. The background that follows offers some broader, thicker, contextualization for my perspectives as well as possible models for approaching the use of games and simulations for learning about religion in the digital age, most importantly, the essential interdisciplinarity between game design literacy, subject matter content knowledge, and pedagogic content knowledge.

My journey to approaching the teaching of religion and culture with games began in grade school in the late 1970 s and early 80 s, designing games on the playground with friends. At summer camp I created more games with friends and learned BASIC programming (Gottlieb, 2014). My oldest friend, Chris Alfieri (my first Dungeon Master for the game Dungeons \& Dragons [Gygax \& Arneson, 1974]), and I designed our own role-playing games. Chris and I went on to use The Games Creator software (Darling \& Darling, 1984) to create our own video games on topics ranging from television infomercials to our favorite Marvel superheroes.

Decades later, in the summer of 2010, I had just been ordained as a Reform rabbi, and was about 
to begin the PhD program at New York University in education and Jewish studies. I had entered rabbinical studies with an eclectic background in software development, dance, film and television writing, and work in the film festival world. I was determined to find ways to help others on their religious learning journeys just as my own unorthodox and Orthodox teachers had helped me. That summer I founded the organization ConverJent: Jewish Games for Learning at CLAL, the National Center for Jewish Learning and Leadership, encouraged by Rabbis Irwin Kula, Brad Hirschfield, and friend and collaborator Peter Pitzele. Through ConverJent, I have designed games for learning and taught workshops and classes on games, game design, and Jewish studies.

While in rabbinical school, I also taught at Jewish supplementary schools (Hebrew schools) for four years and continued to teach while at NYU. I viewed the fellowship that I had received from the Jim Joseph Foundation to pursue my $\mathrm{PhD}$ as an opportunity to bring all my varied experiences to bear on developing innovations using digital media and Games for Learning in Jewish education, and eventually, comparative religion. I decided that I would pursue the study of games, simulations, and learning with faculty in education, communication, and technology (learning sciences) as well as cultural anthropology, and media, culture, and communications. That summer before PhD classes began, I began trying to find connections and potential crossovers between work being done in the burgeoning discipline of Games and Learning design and research and that of Jewish education. As far as I could tell, there had not yet been work done in educational research-informed video games for learning religion.

While formal exploration of games and simulations in education had been going on at least since the 1970s (Gottlieb, 2015, 93), a new branch of Games and Learning concentrating on the attributes of video games had sprouted out of a group of scholars gathered around Jim Gee in the 
early-to mid-2000s at the University of Wisconsin-Madison as well as at other universities including MIT and New York University. Gee (2003) argued that well-made video games provide environments that demand problem solving, opportunities for role-play, just-in-time feedback, and scaffolding for learners. Video games allowed learners to "fail" and try again to solve challenging problems and puzzles. He identified these and many other attributes that are also characteristics of the best learning environments.

Exciting games were being designed for learning, often coming from institutions studying the processes of learning. There were games to teach disciplines such as environmental science (Klopfer \& Squire, 2008), journalistic practices, and engineering (Shaffer, 2006). Constance Steinkeuler (Steinkuehler \& Williams, 2006) was studying learning inside World of Warcraft and Mimi Ito and colleagues were studying digital practices of youth (Ito et al., 2009).

Constructionist scholar Idit Harel Caperton was teaching learners through teaching video game design. Jan Plass, Ricki Goldman, Ken Perlin, and their students at NYU had teamed up with Mary Flanagan at Dartmouth to encourage girls to learn computer programming (Plass, Goldman, Flanagan, \& Perlin, 2009). There were also games designed to teach about topics such as the crisis in Darfur (Darfur is Dying; Ruiz, 2006). I was impressed by Peacemaker from Impact Games (Sweeney, Brown, \& Burak, 2007) which was being used to teach the complexities of the contemporary Israeli-Palestinian conflict by allowing players to strategize towards peace from both sides of the conflict and encounter the many challenges. It was an ambitious project built by a team of designers and subject matter experts.

As I was learning about the emergent field of video Games and Learning, I looked for current research that could align with Jewish studies topics. Jewish studies covers a wide range of topics about Jewish civilization ranging from Biblical philology, archaeology, and hermeneutics to the 
study of philosophy, theology, and mysticism. It includes history from the ancient, medieval, and modern period, and modern and ancient languages including Hebrew, Aramaic, Yiddish, Hittite, Ugaritic, and Akkadian. It covers an array of rabbinic literature including legal, ethical, narrative, and homiletic writing to modern literature, drama, and cultural production. Jewish studies also covers the study of liturgy and synagogue architecture and art and Jewish cultural production. I felt there was such a great treasury to discover, and that through games and digital media, others might find a doorway into the treasures. I wondered: Could I find a way to teach the beauty and complexity of Jewish halachic legal debate? Where would I find the way in?

At the Games for Change conference that summer of 2010 I learned of a history game, Dow Day (Mathews, 2005), designed by Jim Mathews who was studying with Kurt Squire. Dow Day seemed to provide an immediate bridge between Jewish studies subject matter and innovations in Game and Learning technology and design. Dow Day was a place-based, GPS triggered augmented reality game ${ }^{3}$ in which players took on the role of reporters on the University of Wisconsin-Madison campus in 1967. During the Vietnam war Dow Chemical (which manufactured napalm) had come to recruit. Students protested, eventually violence broke out, and students were beaten by police. Players were tasked with interviewing different digital characters as media from 1967 appeared on their mobile devices, triggered to match their physical location on campus. The game played through the history on location. I felt I had found a medium with which I could bring research-based games to Jewish studies.

${ }^{3}$ In augmented reality, digital images or other data are layered on top of "reality" views. In this case, photo and film images and sound from 1967 were displayed on the mobile device when the GPS (Global Positioning System) connected software signaled that the device location matched the location where the footage was originally taken. 
I worked over the next three years to design and develop Jewish Time Jump: New York (Gottlieb \& Ash, 2013). The mobile game, targeted to fifth through seventh grade learners, used a platform called ARIS (developed by David Gagnon, Jim Mathews, Chris Holden, and others) that allowed for the creation of storytelling and gameplay based on the GPS location of the mobile device. Players would "land" in 1909 on the eve of the Uprising of 20,000, the largest women-led strike in U.S. history. Taking on the role of reporters for the fictional Jewish Time Jump Gazette, they would interview a variety of digital characters ranging from labor organizers to manufacturers and immigrants from Ireland and Italy, as well as Eastern European Jewish characters. They would analyze primary sources from the time period, and work to stitch together a story "lost to time." The game situated the Uprising and the subsequent Triangle Shirtwaist Factory fire in the time period, but also contextualized it in broader historical themes, as students learned of a contemporary garment factory collapse in Bangladesh, the labor practices used in making the iPhone upon which they played, and later (through a curriculum cowritten with the Jewish Women's Archive) about contemporary labor concerns in the United States.

After releasing Jewish Time Jump: New York, having learned many lessons through design, research, and work with colleagues, and having built the first bridge between Jewish studies and Games and Learning, I was ready to return to my early ideas about teaching religious legal systems.

Why Teach Legal Codes?

It may not be obvious to all readers why teaching about religious legal codes would be of interest or import. Though not typically taught in supplementary schools, they are a cornerstone of Jewish learning in day schools and at the college and graduate level. This means they are 
little-known outside of intensely Jewish environments, whether scholarly or parochial. Yet legal codes can be of more than arcane interest; these materials often present a window into communal values or governance structures, or as Phillip Ackerman-Lieberman has said (personal conversation), the realpolitik of the time. Indeed, when communities are undergirded by these religious principles, their holistic systems allow them to be sustainable and to thrive. My teacher of medieval philosophy at Hebrew Union College, Rabbi Dr. Leonard Kravitz, went to great lengths to teach us about this aspect of religion. Through these governance structures, I believe we have a window onto what evolutionary biologist David Sloan Wilson $(2011,2013)$ calls the prosocial aspects of religion. We hear little good about religious legal systems in the news these days, as popular reports are unmoored from any historical or contextual understanding of religion. For thousands of years, religions have helped to hold societies together. In the legal codes, we can see the promotion of collaboration and cooperation, and the addressing of issues such as tragedies of the commons ${ }^{4}$ - the need for a community to safeguard communally shared resources. Aspects of these legal systems undergird contemporary legal structures, and in some cases, hold communities to higher standards of communal responsibility. For example, in the laws of lost objects in Mishneh Torah, individuals were expected to go to considerable lengths to care for animals they found, to not benefit from them, but care for them for extended periods while trying to return them (for more detail see Gottlieb, 2017).

The law holds underlying ethical constructs (which as Dr. Kravitz often pointed out to us were also crucial for holding a society or community together), and then demonstrates through

${ }^{4}$ Game designer, collaborator, and colleague, Ian Schreiber (personal conversation) helped me make the connection between the structures I was reading in the Talmud and codes, with game theory issues regarding tragedies of the commons. 
applied cases how living out those constructs could actually work. There is an interplay of tensions evident, for example, in the tort laws, that demands a great deal of service to the community, but also protects individuals from undue burden. The ability to look into the law and investigate specific cases can provide insight into epistemologies of problem solving, and a complex system of what Rabbi Daniel Siegel (personal conversation) described to me as complex weights and measures. The Talmud preserves minority opinions, asks hypotheticals, and sometimes leaves debates unresolved with teku or "let it stand." There is a sense, in both the concern with outlier cases in the Talmud, and the specificity of cases in the codes, such as Mishna or Mishneh Torah, that exceptions to rules are important, and the preservation of these exceptions points to principles underlying the laws. Given exceptions, how would one judge what is right or just without referring back to principle?

While the realpolitik of governance may not be viewed by some scholars of religion as "religious expression," it is very much a part of religious civilization and the lived experience of religion. The study of these laws has been historically, and is for many today, an act of religious devotion. For Orthodox and many Conservative Jews, the study of the laws such as those of Kashrut (Kosher dietary restrictions and rules), prayer, and Shabbat observance, are likely more immediately related to daily religious life than medieval tort law, yet the study of the tort law is also devotional practice and can transmit those underlying principles such as obligations to neighbors.

From the wider perspectives of both the secular study of religious legal systems and religious education, the laws provide insight into history, communal norms, community building and sustainability, and styles and approaches of reasoning and problem solving within the religious 
context. There is a great deal to learn from the legal systems as literature, as practical philosophy and theology, and as history.

From the standpoint of a researcher and designer of Games for Learning, a turn to teaching the law is a logical step. Just as case-law considers a variety of hypotheticals and outcomes (Gottlieb, 2015, 2017), games can instantiate hypothetical outcomes through play: "What if player X did Y when confronted with this case? What if player X did Z? What if another player decided to intervene?" By designing a rule and event system, a game designer can set players in motion to play out a variety of choices, decisions, and approaches to a given scenario. Given this characteristic of games systems as modeled decision systems, the next logical step was to develop a game that moved elements of a legal code from the rule-based system of laws to a modeled rule-based game system. So, how can designers of learning games approach de-coding the legal code?

Talmudic Hermeneutics for Game Design for Teaching Religion

My approach to designing religious legal games has been significantly influenced by two methods I learned from my teachers of Talmud, and both informed the pedagogical content knowledge with which I taught the team about Jewish law. When I was learning to study Talmud, Rabbi Dr. Michael Chernick's methodology helped guide me from seeing a page of arcane text to an understanding of the meaning of a religious legal debate. Chernick's methodology for approaching Talmudic legal argumentation consisted of four levels. First, translation; then outlining the argumentation; then developing an understanding of the halachic (Jewish legal) argument; and finally, considering the theological underpinning or implications (Chernick, lectures at Hebrew Union College; Chernick, personal conversation; see also Chernick, 2013). What do each of these levels mean? Translation involved both Hebrew text and 
the Aramaic rhetorical phrases used in the framing of the argument in the Babylonian Talmud. We used Talmudic dictionaries to place the language in the right register, or period of Hebrew or Aramaic, and contextualized meaning. Outlining the argumentation often meant splitting apart a complex set of nested queries and then logically charting the arguments. Trying to understand the implications of the highly elliptical passages required untangling, and the outline form helped us follow the flows of the different parts of the legal argument. When the design team on Lost \& Found was analyzing laws from Mishneh Torah's chapter Gezelah Va'Avedah (robbery and lost objects), we often ended up charting and outlining cases as a way to examine the case law.

Chernick's third step is understanding the halachic argument - what specific halachic concepts are in play or of concern. This was a different level, beyond standard argumentation, as it requires understanding terms of art. We spent a great deal of time in the design of Lost \& Found working to understand and communicate notions such as the legal status of an owner having "despaired of the loss" of the object, sometimes translated as "forsaken hope of finding" the object. This refers to a legal status of an object based on the owner both realizing the item is lost and the low likelihood that the owner will find the object, as opposed to a willful abandonment, which had to be witnessed. So, for example, coins found on a flooded river bed, even if found in a marked wallet, lose their status of ownership by the original owner as it is assumed the owner has "forsaken hope of finding them." We reasoned that part of the import of this legal status was to prevent undue burden on the finder, who otherwise may be required to track down the owner. In understanding a halachic argument, one first has to understand the referenced concepts and what is at stake in the argument.

Chernick's fourth step is to examine the theological underpinnings of the debate. How does the debate reflect principles - values as understood in the context of religious obligation, moral 
obligation, and God? For example, once one understands the legal reasoning behind not holding a finder responsible for returning coins in the bed of a flooded river and even allowing the finder to keep them, how might this be interpreted theologically? While legal reasoning might turn to notions of preventing undue burden on the part of the finder, as well as taking into account limited ability to enforce the law, a considering of theological implications might point to circumscription by the law as demonstration of an underlying value. For example, "If this river case is the kind of specific outlier case in which keeping what one finds is allowed, then how important is it to get most objects back to the owner?" Tort law tends to show the realpolitik more than the theological, yet the notions of the underlying value still remain in this model, one step removed from the legally reasoned argument. While the design team did not concentrate on theological issues in the design process, the opportunities to teach these concepts through the game is embedded in the laws themselves.

Rabbi Dr. Eliezer Diamond taught me a different approach to interpreting Talmud, drawing from transactional analysis as articulated in the book Games People Play (Berne, 1996). Berne looks at conversations between people as transactions, enacted for a purpose; that purpose, however, is seldom stated in the text of the discourse, but can rather be found the subtext, or as a second-order game. Diamond suggests that the Talmudic debates often raise an argument for a purpose, yet that purpose may not be obvious. Therefore, asking meta questions around what the purpose of the debate might actually be forms another hermeneutic tool. Berne includes such interpersonal "games" as "See What You Made Me Do," "If It Weren't for You," and "Let's You and Him Fight." These titles give a hint about routines or games played out between people with ulterior motives. Likewise, Diamond suggests that Talmudic debates may have a beyond-thesurface agenda, and that a debate about one topic may be presented for a different purpose. 
As the Lost \& Found team dissected laws in Mishneh Torah, we too found ourselves asking "Why is this important?" and "Why does the law makes this claim? What is the principle it is addressing or the problem that it is trying to solve?" While the rhetorical game is seldom at the complex level of a Talmudic debate, the way in which the law case is written uses specific examples to suggest broader principles. In the process of designing the games, we had to reach for the broader principles, sometimes reviewing the other laws in the chapter, using footnotes from our secondary source (Touger, 1997), and discussing with our consulting experts.

The use and influence of these hermeneutical approaches leads to the exploration of two kinds of teaching and learning with Lost \& Found.

Game Design and Game Play

Games for Learning should not be understood as stand-alone artifacts. Learning researchers also understand that the games and simulations function within a curriculum (Bauman \& Games, 2011; Hays, 2005; Sitzmann, 2011; Squire, 2010). Games designed for learning, at least ones based on research in the field, should be concerned with learning mechanics - that the actions taken in the game to achieve player goals are related to the learning behaviors that educators and researchers determine are aligned with learning goals (Gottlieb \& Schreiber, forthcoming; Plass, Homer, Kinzer, Frye, \& Perlin, 2011).

There are at least two kinds of teaching and learning occurring around the Lost \& Found games: learning processes within the design team and learning processes by external players. I will address each in turn. There is a longstanding body of knowledge around the kind of learning that happens during the design process. Constructionists have been concerned with the approach of learning through design (Harel \& Papert, 1991; Reynolds \& Caperton, 2011). When considering teaching and learning in the context of the design project, I include the design 
activities, the artifacts or output of the design (the games), as well as internal design reviews and discussions of the game during iterative playtest cycles. As alluded to above, the Lost \& Found team had to perform textual analysis of the laws to come to an understanding of their meaning. The team worked with experts like Phillip Ackerman-Lieberman, one of our key consulting experts in Jewish and Islamic law, on everything from accuracy in rendering images of objects from the period, to understanding interrelationships between laws.

The design team also worked together on ways to model the system of people living with the law. Over various iterations this system included resources such as coins and currency, livestock, garments, food, and vessels. The system had to incorporate and consider interrelationships between players, interdependencies, and communal needs, as well as individualized incentives. In terms of choices, the design team had to build ways into the system in which players would make decisions regarding the treatment of their neighbors and to what extent they would follow or not follow the law. This is in the context of the dual-design problem of how to render an engaging game in a limited amount of play time and how to convey legal situations that could be made into reflective moments for the player. From the amount of time spent pouring over the texts during three plus years of work, in consultation with faculty on the games at RIT, those on the game design team mastered a certain level of expertise of the text. They also participated in the production of finished, "shipped" games, helped teach others how to play, and communicated with other team members about aspects of the laws. Those who were not concentrating on the legal systems helped in proofreading and quality assurance tasks on the legal rulings appearing on the cards. Graduate and undergraduate students designed side-by-side, debating and considering potential implications of design decisions, reviewing playtests with faculty, and developing approaches to address issues discovered in playtesting. 
Might this be a way for others at the university level to approach the teaching of complex legal and theological topics - creating design objects and artifacts? There are a few other factors to take into account. First is the level of expertise of the faculty. Perusing the design work requires subject matter expertise, which in this case was combined across faculty both at RIT and other participating institutions, as well as game design skills. In addition to my own previous work in game design, our core mechanics game designer was Ian Schreiber, my colleague at RIT, who has over 16 years of industry experience in game design. For educators considering game design as a means of teaching religion topics, having game and game design literacy is critical. In addition to firsthand facility with a variety of game genres, I recommend that educators begin their game literacy with two texts: Tracy Fullerton's Game Design Workshop (2014), now in its third edition (soon to be in fourth edition), and the graduate-studies-level text Rules of Play: Game Design Fundamentals (Salen \& Zimmerman, 2003). Time is an additional factor to consider. Game design is time consuming and so an educator must be sufficiently practiced in game design in order to determine the optimal exercises with students given the length of time available.

Players external to the design also engage in learning processes during and after play. Beyond internal design reviews, playtests, and observations of the processes that have thus far gone into the designed artifact, the team's study of learning through play in the context of Lost \& Found is at the early stages. I have been working with my colleague David Simkins in the field, observing teen players with video and audio observations, using semi-structured interviews and group discussion. We analyze the talk-practice (speech acts used as evidence in anthropology and other social science) of players. We have a small " $n$ " size currently but are expanding our field studies. That said, preliminary analysis suggests that the discourse around the strategy game required 
particular moderator scaffolding in order to move from the abstracted play to second-order considerations of the law, such as ethics, and discussions of why the law may have been structured as it was structured. For example, the players in the strategy game may discuss amongst themselves how they can work together to address a communal need or crisis, though that talk may be in the form of the numerical value of various resources to contribute to a communal need. In the absence of prompting from a moderator, players have not yet discussed the underlying meaning of how the laws related to communal collaboration. Such conversations have required curricular and moderator scaffolding.

We assume, as discussed above, that Games for Learning require and are to be used within curricula; however, as learning game designers, we are always also experimenting with designing game mechanics (those actions a player repeats throughout the game to achieve goals) and developing those mechanics' relationships to different learning behaviors. Ian Schreiber and I began to investigate what kind of game mechanics would shift players immediately into discussion of legal reasoning and implications. Order in the Court grew out of that investigation with the design team. Players immediately begin theorizing on the rationale behind the laws and what they might mean. Through iterations, internal design reviews, and playtests, we shifted play away from rewarding players for the judge's choice of favorite story and for accuracy of the answers (how close players could get to the medieval and legal reasoning). Accuracy had been determined using a booklet of answers we created and provided to the judge. We removed the secondary rewards system based on accuracy, and kept the judge's choice of favorite story (whether based on humor or any other criteria the judge would use), while placing the explanation on the reverse of the Ruling card. Players in internal design playtests began asking for the explanation, which could potentially demonstrate the generation of curiosity. Our next 
step will be to test these design team theories with further external, IRB social science investigations. Order in the Court provides a very different kind of game experience than Lost \& Found does. Each game requires different curricular scaffolding, and can be used in concert for the generation of different kinds of learner discourse and discussion, with Lost \& Found setting up opportunities for delving into player collaborations and competitions, and Order in the Court providing quick opportunities to engage in discussions of legal reasoning.

\section{Conclusions}

This design case has explored the context leading to and the development of two games for learning that use very different game mechanics and approaches to teaching subject matter. The games originated from the desire to merge Jewish learning with contemporary Games for Learning, and from the desire to explore the potential interconnection between games and religious legal systems given their nature as essentially rule-based systems. How might law codes that were dedicated to realpolitik such as governance, and were simultaneously undergirded by theological principles and constructs, find a new kind of pedagogical form in contemporary game systems? These curiosities and questions led to years of iterative design work between faculty and students exploring subject matter as well as experimenting with various approaches to game design. The game design was player-centered through regular playtesting and focused on generating both meaningful play and opportunities for curricular development. The games were envisioned not only as rich set inductions, but also as providing rich cases for analysis through the act of playing through situations.

The processes of creating the games combined subject matter knowledge in Jewish studies ranging from history to law to architecture and beyond. Faculty brought a variety of knowledge to the table and students and faculty studied material together during design, learning in the 
process of working to translate that content knowledge into game form. At the same time, a parallel process of accruing game design knowledge developed as faculty led design while students actively participated and contributed to design conversations (Gottlieb, 2017). The pedagogical content knowledge developed similarly. I brought exegetical methods for studying religious law that I learned from Chernick and Diamond to the design team, allowing us to delve into and unpack the texts. Then, as faculty worked on our small study with teens, we also developed new hypotheses of how the games could potentially be built into curriculum. The second game originated out of our new pedagogical content knowledge and our curiosity as to whether we could shift discourse from trade-off decisions to a meta-legal analysis. And so, the iterative and exploratory cycles occurred in all through knowledge areas. As our research proceeds, we will develop and integrate curriculum for the games, while expanding the series as we gather and analyze data from play.

Working with a diverse set of experts makes games in particular subject matter areas possible, as different voices add to the project and provide depth and breadth across content knowledge, pedagogic content knowledge, and design knowledge. Using the expertise of the Games and Learning community and built by learning scientists ${ }^{5}$ and researcher-designers across a broad spectrum, over a decade of research is now available to help inform new work in games and religion. At the same time, given that little Games and Learning work has been done in new design for religious learning and literacy, there is also an opportunity to expand the research, design, and literature in this area.

\footnotetext{
${ }^{5}$ For an introduction to the Learning Sciences, I recommend Sawyer's The Cambridge Handbook of the Learning Sciences, $2^{\text {nd }}$ edition (Sawyer, 2014).
} 
Examining and teaching legal systems provides the opportunity to explore pro-social aspects of religion. Legal systems hold implications not only for theological and ethical decision making, but for governance structures, both centuries old and contemporary. They can provide a platform for seeking to understand religious law in historical and geographical contexts. Unlike contemporary law, the medieval codes often preserved specific situated struggles. While not the most efficient structure of writing a legal code, they can provide specific and provocative cases for play - opportunities for discussion.

At a time when governance and democracy are being challenged in new ways, it is especially relevant to see how even just a few verses in Deuteronomy could lead to extensive governance structures, structures that pre-figure modern day legal systems. With games, we can explore these models of governance for hints about how we might find better ways to collaborate and cooperate today while developing new knowledges for teaching, learning, and designing.

\section{Bibliography}

Bauman, E. B., \& Games, I. A. (2011). Contemporary theory for immersive worlds: Addressing engagement, culture, and diversity. In A. Cheney, \& R. Sanders (Eds.), Teaching and learning in 3D immersive worlds: Pedagogical models and constructivist approaches (pp. 248-270). Hershey, PA: IGI Global. https://doi.org/10.4018/978-1-60960-5179.ch014. Retrieved from https://www.igi-global.com/gateway/chapter/52402

Berne, E. (1996). Games people play: The basic handbook of transactional analysis. New York, NY: Ballantine Books. 
Boling, E. (2010). The need for design cases: Disseminating design knowledge. International Journal of Designs for Learning, 1(1), 1-8. Retrieved from https://doi.org/10.14434/ijdl.v1i1.919

Chernick, M. (2013). Neusner, Brisk, and the Stam: Significant methodologies for meaningful Talmud teaching and study. In J. A. Levisohn, \& S. P. Fendrick (Eds.), Turn it and turn it again: Studies in the teaching and learning of classical Jewish texts (pp. 105-126).

Brighton, MA: Academic Studies Press. Retrieved from http://bir.brandeis.edu/handle/10192/32750

Darling, D., \& Darling, R. (1984). The games creator (Codemasters version) [Software]. Retrieved from http://creatools. gameclassification.com/EN/creatools/33-The-GamesCreator/index.html

Fullerton, T. (2014). Game design workshop: A playcentric approach to creating innovative games (3rd ed.). Boca Raton, FL: A K Peters/CRC Press.

Gee, J. P. (2003). What video games have to teach us about learning and literacy. New York, NY: Palgrave Macmillan.

Gottlieb, O. (2014). Nurturing Jewish playmakers: Schwartz Tag, good video games, and futures of Jewish learning. In D. Bryfman (Ed.), Experience and Jewish education (pp. 197204). Los Angeles, CA: Torah Aura Productions.

Gottlieb, O. (2015). Jewish games for learning: Renewing heritage traditions in the digital age. In H. Campbell (Ed.), Digital Judaism: Jewish negotiations with digital media and culture (pp. 91-109). New York, NY: Routledge. Retrieved from http://www.routledge.com/books/details/9780415736244/ 
Gottlieb, O. (2017). Finding Lost \& Found: Designer's notes from the process of creating a Jewish game for learning. Gamevironments 7, Special Issue: Jewish Gamevironments, $42-65$.

Gottlieb, O., \& Ash, J. (2013) Jewish Time Jump: New York [Video game]. ConverJent.

Gottlieb, O., Herold, D., \& Amidon, E. (2017). Card tricks: A workflow for scalability and dynamic content creation using Paper $2 D$ and Unreal Engine 4. Presented at the Foundations of Digital Games 2017 Conference, Cape Code, MA. Retrieved from http://fdg2017.org/papers/FDG2017_demo_CardTricks.pdf

Gottlieb, O., \& Schreiber, I. (2017). Lost \& Found: Order in the Court - the Party Game [Card Game]. MAGIC Spell Studios, LLC.

Gottlieb, O., \& Schreiber, I. (forthcoming). Designing analog learning games: Genre affordances, limitations, and multi-game approaches. In E. MacCallum-Stewart, \& D. Brown (Eds.), ReRolling Board Games. Jefferson, NC: McFarland Press.

Gottlieb, O., Schreiber, I., \& Murdoch-Kitt, K. (2017). Lost \& Found [Board Game and Video Game Prototype]. MAGIC Spell Studios, LLC.

Gygax, G., \& Arneson, D. (1974). Dungeons and Dragons [Role-Playing Game]. TSR.

Harel, I., \& Papert, S. (1991). Constructionism: Research reports and essays, 1985-1990. Norwood, NJ: Ablex Pub. Corp.

Hays, R. T. (2005). The effectiveness of instructional games: A literature review and discussion. Retrieved from http://www.dtic.mil/docs/citations/ADA441935

Heller, M. J. (1995). Designing the Talmud: The origins of the printed Talmudic page. Tradition: A Journal of Orthodox Jewish Thought, 29(3), 40-51. https://doi.org/10.2307/23260840 
Howard, C. D. (2011). Writing and rewriting the instructional design case: A view from two sides. International Journal of Designs for Learning, 2(1), 40-55. https://doi.org/10.14434/ijdl.v2i1.1104

Ito, M., Horst, H. A., Antin, J., Finn, M., Law, A., Manion, A., .. Yardi, S. (2009). Hanging out, messing around, and geeking out: Kids living and learning with new media. Cambridge, MA: The MIT Press.

Jewish Publication Society (Ed.). (1985). Tanakh: The Holy Scriptures - The new JPS translation according to the traditional Hebrew text. Philadelphia, PA: The Jewish Publication Society. Electronic Version. Version 2.9.

Klopfer, E., \& Squire, K. (2008). Environmental detectives - The development of an augmented reality platform for environmental simulations. Educational Technology Research \& Development, 56(2), 203-228. https://doi.org/10.1007/s11423-007-9037-6

Levisohn, J. A., \& Fendrick, S. P. (Eds.). (2013). Turn it and turn it again: Studies in the teaching and learning of classical Jewish texts. Brighton, MA: Academic Studies Press. Retrieved from http://bir.brandeis.edu/handle/10192/32750

Mathews, J. (2005). Dow Day [Video game]. Jim Mathews.

Plass, J. L., Goldman, R., Flanagan, M., \& Perlin, K. (2009). RAPUNSEL: Improving selfefficacy and self-esteem with an educational computer game. Proceedings of the 17th International Conference on Computers in Education [CDROM], 682-689.

Plass, J., Homer, B., Kinzer, C., Frye, J., \& Perlin, K. (2011). Learning mechanics and assessment mechanics for games for learning. Retrieved from 
https://www.researchgate.net/publication/272815253_Learning_Mechanics_and_Assess ment_Mechanics_for_Games_for_Learning

Reynolds, R., \& Caperton, I. H. (2011). Contrasts in student engagement, meaning-making, dislikes, and challenges in a discovery-based program of game design learning. Educational Technology Research and Development, 59(2), 267-289. https://doi.org/10.1007/s11423-011-9191-8

Rosenberg, U. (2007). Agricola [Board game]. Lookout Games.

Ruiz, S. (2006). Darfur is Dying [Video game]. Susana Ruiz, TAKE ACTION games.

Salen, K., \& Zimmerman, E. (2003). Rules of play: Game design fundamentals. Cambridge, MA: The MIT Press.

Sawyer, R. K. (Ed.). (2014). The Cambridge handbook of the learning sciences (2nd ed.). New York, NY: Cambridge University Press.

Shaffer, D. W. (2006). How computer games help children learn. New York, NY: Palgrave Macmillan.

Shulman, L. S. (1986). Those who understand: A conception of teacher knowledge. American Educator, 10(1), 9-15. 43-44

Sitzmann, T. (2011). A meta-analytic examination of the instructional effectiveness of computerbased simulation games. Personnel Psychology, 64(2), 489-528. https://doi.org/10.1111/j.1744-6570.2011.01190.x

Smith, K. M. (2010). Producing the rigorous design case. International Journal of Designs for Learning, 1(1), 9-20. https://doi. org/10.14434/ijdl.v1i1.917 
Squire, K. (2010). From information to experience: Place-based augmented reality games as a model for learning in a globally networked society. Teachers College Record, 112(10), $2565-2602$.

Steinkuehler, C. A., \& Williams, D. (2006). Where everybody knows your (screen) name: Online games as "third places." Journal of Computer-Mediated Communication, 11(4). Retrieved from http://onlinelibrary.wiley.com/ https://doi.org/10.1111/j.10836101.2006.00300.x/full

Sweeney, T., Brown, E., \& Burak, A. (2007). Peacemaker [Video game]. Impact Games.

Teuber, K. (1996). The Settlers of Catan [Board game]. Mayfair Games.

Touger, E. (1997). Rambam Mishneh Torah: Sefer Nezikin. New York, NY: Moznaim Publishing.

Wilson, D. S. (2011). The neighborhood project: Using evolution to improve my city, one block at a time. New York, NY: Little, Brown and Company.

Wilson, D. S. (2013, October 17). Evolving a city. On Being Podcast. Podcast retrieved from https://onbeing.org/programs/david-sloan-wilson-evolving-a-city/ 